\title{
Pierre Gisel,Serge Margel (dir.), Le croire au cœur des sociétés et des cultures. Différences et déplacements
}

Turnhout, Brepols, 2011, 235 p.

Rodolfo de Roux

\section{OpenEdition}

Journals

Édition électronique

URL : http://journals.openedition.org/assr/26427

DOI : $10.4000 /$ assr.26427

ISSN : $1777-5825$

Éditeur

Éditions de l'EHESS

Édition imprimée

Date de publication : 31 décembre 2014

Pagination : 194

ISBN : 978-2-7132-2467-6

ISSN : 0335-5985

\section{Référence électronique}

Rodolfo de Roux, «Pierre Gisel,Serge Margel (dir.), Le croire au cœur des sociétés et des cultures. Différences et déplacements », Archives de sciences sociales des religions [En ligne], 168 | 2014, mis en ligne le 29 avril 2015, consulté le 22 septembre 2020. URL : http://journals.openedition.org/assr/ 26427 ; DOI : https://doi.org/10.4000/assr.26427 


\section{Pierre Gisel,Serge Margel (dir.), Le croire au cœur des sociétés et des cultures. Différences et déplacements}

Turnhout, Brepols, 2011, 235 p.

Rodolfo de Roux

\section{RÉFÉRENCE}

Pierre Gisel,Serge Margel (dir.), Le croire au cœur des sociétés et des cultures.

Différences et déplacements, Turnhout, Brepols, 2011, 235 p. 
1 Issu d'un colloque organisé sous les auspices conjoints de l'École pratique des hautes études (Paris) et de l'Université de Lausanne, cet ouvrage collectif aborde le «croire» non d'abord comme un assentiment, une adhésion mentale à des représentations ou à des propositions, mais comme moment de pratiques effectives et d'insertion d'un sujet dans une communauté, une mémoire, un héritage ou une histoire. Il s'agit donc, avant tout, d'une pratique du croire.

2 Comme le soulignent P. Gisel et S. Margel dans leur "Ouverture » de l'ouvrage, le croire, parce qu'inscrit dans une pratique et une histoire, se tient au cœur de ce qui fait nos adhésions, au cœur du «lien social». Mais, si le croire assure du lien social, il est en même temps le lieu de son

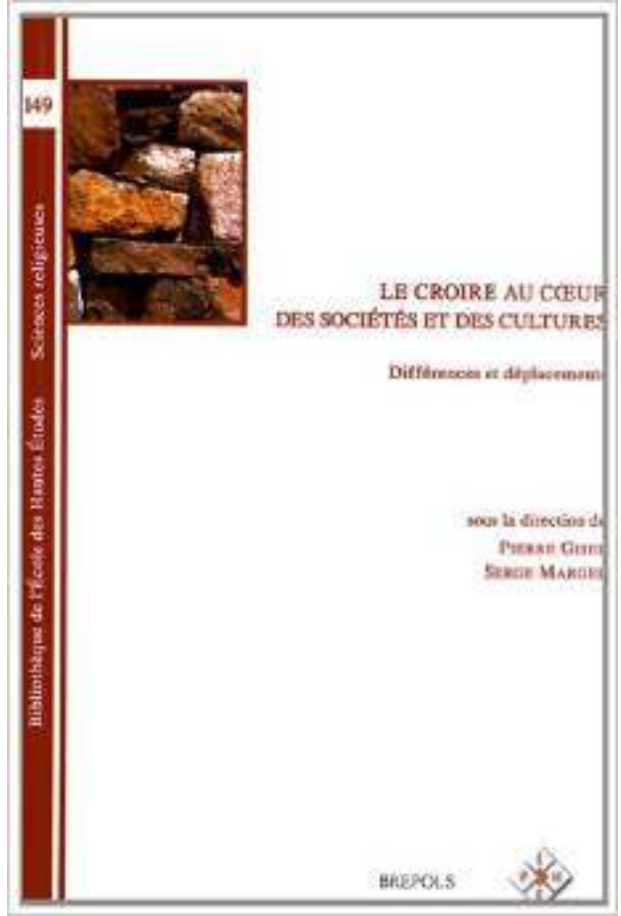
instabilité puisque le croire suppose de l'incertitude et de l'indéterminé; il est lieu de différentiations. Ce double aspect du croire - lien social et lieu de différentiations - traverse ce savant ouvrage organisé en trois parties, chacune étant précédée d'une utile « mise en perspective » qui explicite la problématique et les angles d'approches des différentes contributions. Par rapport à un Occident chrétien, la première partie, « Décentrements ", porte un regard sur d'autres civilisations et d'autres traditions. La deuxième partie, «Une histoire différenciée. Relectures ", aborde quelques aspects de l'histoire du croire dans le monde chrétien européen. La troisième partie, « Données contemporaines et reprises réflexives », ouvre des perspectives sur le croire à partir de réalités contemporaines.

La première partie, qui convoque à un décentrement de l'histoire occidentale marquée par le christianisme s'arrête à quatre moments : l'Antiquité préchrétienne, l'ExtrêmeOrient confucéen, le judaïsme et l'islam. Le premier texte, de Philippe Borgeaud (Université de Genève), reprend l'interrogation sur les croyances à partir des pratiques, voire des coutumes, et montre une Antiquité préchrétienne tolérante parce que hors révélation divine singulière, revendicatrice et impérieuse. Mais cette tolérance ne va pas sans limites puisque l'étranger peut confiner au barbare ou au sauvage et ses pratiques religieuses être dites superstitieuses. Le deuxième texte, de Myung-Su Yang (Ewha Womans University, Séoul), présente le confucianisme comme confiance interhumaine, en lien fort avec l'ordre social. On parlera là de croyance, mais c'est dans le strict cadre de pratiques morales à déployer. Sylvie Anne Goldberg (EHESS, Paris) réfléchit sur une "transformation de la grammaire du croire » dans le judaïsme au cours du temps, notamment au Moyen Âge, sans oublier d'évoquer la complexité de la pratique du croire dans le judaïsme d'aujourd'hui. Enfin, le texte de Pierre Lory (EPHE, Paris), vise à décrire l'acte de foi en islam sunnite, donc non tant le contenu de la foi que ce à quoi elle engage.

4 La deuxième partie invite à des différentiations sur la question du croire, de son statut et de ses formes à l'intérieur du christianisme. Le premier texte, de Catherine König- 
Pralong (Université de Fribourg et Université Paris IV-Sorbonne), sur les «situations et fonctions sociales du croire dans la scolastique médiévale » fait voir qu'il y a eu du différend entre les théologiens qui tendaient à penser le croire dans l'ordre d'une anthropologie générale et ceux qui tendaient à le rapporter à une donne institutionnelle. Avec les deux textes suivants, on se tient au départ des Temps modernes. Le texte de Pierre Antoine Fabre (EHESS, Paris) se consacre au moment où le catholicisme qui naît avec le Concile de Trente et la Contre-Réforme construit un temps et un espace, infinis, pour " croire en l'avenir du monde ", en riposte à l'effondrement de l'ordre symbolique qui sous-tendait le Moyen Âge. La contribution de Jad Hatem (Université Saint-Joseph de Beyrouth), en prenant l'exemple de Thérèse d'Avila examine comment le problème de la foi se pose dans la théologie mystique d'une façon originale et aiguë. Le quatrième et dernier texte, de Sarah Scholl (Université de Genève), fait une analyse des dimensions sociale, ecclésiale et politique du croire dans la Genève des années 1860-1880 et montre dans quelle mesure le cas genevois est un « laboratoire » particulièrement éclairant des recompositions du croire des dernières décennies du XIX ${ }^{e}$ siècle.

5 La troisième et dernière partie du volume comporte deux aspects. D'abord, des terrains contemporains où la question du croire peut être relancée. Ensuite, quelques facettes d'une reprise, problématisante et réflexive, supposant l'ensemble du chemin parcouru. Pour le premier aspect, Laurent Amiotte-Suchet (Université de Lausanne) fait une réflexion anthroposociologique à partir des «croyances » d'un pèlerin de Lourdes, en mai 2009. À son tour, Xavier Gravend-Tirole (Université de Lausanne) consacre sa contribution au phénomène de la fidélité à deux religions et du « croire écartelé » en se concentrant sur le terrain de l'Inde et du christianisme hindou. Les trois textes suivants, plus délibérément réflexifs et problématisants, reprennent ce qui se joue avec la ou les "croyances». Serge Margel (Université de Lausanne) rappelle combien le concept de croyance embarrasse les sciences humaines et tout particulièrement les sciences des religions. Jean-Daniel Causse (Université Paul-Valéry-Montpellier III) analyse la dialectique de la croyance et de la foi au regard de la psychanalyse de Lacan. Par la suite, Pierre Gisel (Université de Lausanne) reprend la question de la croyance en ce qu'elle est de fait à l'œuvre dans les jeux où se posent et se constituent les corps, la représentation, ce qui échappe ou ne s'intègre pas. Pour conclure, Jean-Paul Willaime (EPHE, Paris) prend le parti d'un libre propos sociologique en écho aux réflexions développées dans l'ensemble des contributions et nous offre "quelques réflexions sur les dynamiques contemporaines du croire ».

6 À partir de dossiers très divers et de disciplines différentes, cet ouvrage apporte des éclairages et des questionnements multiples sur le phénomène du croire (ses modes de régulations et d'institutionnalisations; la place et rôle des croyants dans les fonctionnements sociaux ; les modalités différentes du croire, etc.). Il a aussi le mérite de décentrer l'étude du croire des visions christiano - et occidentalo - centrées en montrant la pertinence de la question pour d'autres cultures et traditions religieuses. 